\title{
POR UM MODELO PASSO A PASSO PARA A LEITURA E ESCRITA DE TEXTOS: Em fOCO, "O Bicho" de Manuel Bandeira
}

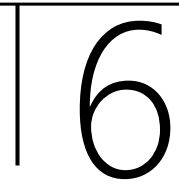

\section{BY A STEP-BY-STEP MODEL FOR READING AND WRITING TEXTS: In focus, "O Bicho" by Manuel Bandeira}

\section{SANTOS, Valdenildo dos}

Doutor em Letras, Filologia e Linguística Portuguesa (Semiótica) pela UNESP

Pós-Doutor em Languages and Cultures pela Purdue University, West Lafayette, Indiana, Estados Unidos (2016-2018),

Professor associado na Universidade Federal de Mato Grosso do Sul, Campus de Três Lagoas,

E-mail: sotnas2021@gmail.com

ORCID ID: https://orcid.org/0000-0002-6224-6650

\section{RESUMO}

Este texto fala sobre pesquisas (2011-2020) e aplicabilidade da teoria greimasiana em poema no Brasil e nos Estados Unidos em torno de um modelo passo à passo para a leitura e escrita de textos atendendo a um anseio de Greimas que falava sobre a "vulgarização" da ciência, palavra que em francês dá-nos a conotação de "popularização". Seu foco, no entanto, são as pesquisas realizadas em solo americano, por meio de parte de um projeto pós-doutoral, no estado da indiana. A experiência foi realizada com um grupo de alunos de Língua Portuguesa da grade do Departamento de Artes Liberais, setor de Língua Portuguesa, no inverno de 2017, ao qual foi apresentado o poema "O Bicho" de Manuel Bandeira para uma interpretação anterior e outra posterior à apresentação de um modelo passo à passo para a leitura objetiva do texto.

Palavras-Chaves: Modelo passo à passo, Semiótica, Poema, Literatura.

\section{ABSTRACT}

This one talks about research (2011-2020) and the applicability of Greimasian theory in poems in Brazil and the United States around a step-by-step model for the reading and writing of texts meeting a desire of Greimas who spoke about the "vulgarization" of science, a word that in French connotes "popularization". His focus, however, is research carried out on American soil, through part of a post-doctoral project, in the state of Indiana. The experience was carried out with a group of Portuguese Language students from the Department of Liberal Arts, Portuguese Language sector, in the winter of 2017, 
to whom the poem "O Bicho" by Manuel Bandeira was presented for an earlier and later interpretation before and after a presentation of a step-by-step model for the objective reading of the text.

Keywords: Step-by-step model, Semiotics, Poem, Literature.

\section{POR UM MÉTODO PASSO A PASSO PARA A LEITURA E ESCRITA DE TEXTOS}

O modelo de Greimas (1979, p. 209), já no final dos anos setenta, apresentou um esquema para mostrar o caminho que gera o sentido dentro do texto, privilegiando o que o texto diz, da maneira como diz o que diz, buscando-se a objetividade na leitura de um texto. Você não precisa ir ao contexto para explicar o texto, mas faz o caminho inverso. Do texto (enunciado) você chega ao contexto, ao amplo mundo da enunciação.

É baseado no modelo de Greimas que a ideia de disseminar a teoria e fornecer aos alunos um método "passo a passo" para leitura/escrita parece ser uma proposta para a abertura de sua percepção em relação ao sentido dentro de um texto. As pesquisas no Brasil (2014-2016) serviram de base para a experimentação nos Estados Unidos, quando 99\% dos 200 alunos da rede pública de ensino de Três Lagoas e Andradina demonstraram não ter um norte para iniciar o processo de leitura dos textos que lhes foram apresentados ${ }^{1}$. A pergunta que mais se ouviu foi: por onde eu começo? Eis o modelo de Greimas da década de 70:

\footnotetext{
${ }^{1}$ Ver (ler) publicações "Semiótica e a formação de professores de português e literatura de Três Lagoas" (2014), "Leitura crítica na Escola Pública Luiz Lopes de Carvalho" (2015), dissertação de mestrado "Semiótica em sala de aula: uma proposta para a ampliação do modo de ver (ler) o texto" (2016), "Semiótica Aplicada ao ensino: Uma experiência didática com o texto não verbal" (2016), "Experiência didática por meio da semiótica aplicada em "Canção para minha morte" de Manuel Bandeira" (2016), "Interface metacognição e semiótica para a leitura de textos sincréticos" (2017), "Gênero histórias em quadrinhos, Metacognição e Semiótica como motivação para leitura e escrita críticas na sala de aula" (2017).
} 


\begin{tabular}{|c|c|c|c|}
\hline \multicolumn{4}{|c|}{ O PERCURSO GERATIVO DO SENTIDO } \\
\hline & & Componente sintático & Component e Semântico \\
\hline \multirow{2}{*}{$\begin{array}{l}\text { Estruturas } \\
\text { Semio- } \\
\text { narrativas }\end{array}$} & $\begin{array}{l}\text { Nível } \\
\text { Profundo }\end{array}$ & $\begin{array}{l}\text { SINTAXE } \\
\text { FUNDAMENTAL }\end{array}$ & $\begin{array}{l}\text { SEMÂNTICA } \\
\text { FUNDAMENTAL }\end{array}$ \\
\hline & $\begin{array}{l}\text { Nível de } \\
\text { superfície }\end{array}$ & $\begin{array}{l}\text { SINTAXE } \\
\text { NARRATIVA } \\
\text { DE SUPERFÍCIE }\end{array}$ & $\begin{array}{l}\text { SEMÂNTICA } \\
\text { NARRATIVA }\end{array}$ \\
\hline $\begin{array}{l}\text { Estructuras } \\
\text { Discursivas }\end{array}$ & & VTAXE DISCURSIVA & $\begin{array}{l}\text { SEMÂNTICA DISCURSIVA } \\
\text { Tematização } \\
\text { Figurativização }\end{array}$ \\
\hline
\end{tabular}

Por onde eu começo? Buscando-se a resposta para essa pergunta surge a proposta que vem sendo aplicada junto a alunos no Brasil (20142016) e nos Estados Unidos (2017), cujos resultados nos fazem acreditar que a teoria de Greimas, se bem trabalhada em sala de aula, tem muito a contribuir quanto à análise objetiva do texto e à ampliação da capacidade de percepção do sentido no interior do texto.

Da experiência realizada com os seis alunos da Purdue University, 12 alunos da Universidade de Oklahoma e centenas de alunos da rede pública de ensino americano nos Estados Unidos (2016-2018), surgiu essa proposta que segue:

I. Leia todo o texto e faça um resumo em um primeiro parágrafo. Lembre-se que um resumo é uma síntese dos principais pontos de um texto. Escreva seu resumo como primeiro parágrafo, como a introdução do seu artigo.

II. Leia todo o texto novamente e procure o que é eufórico (positivo) e disfórico (negativo) do ponto de vista do narrador. Escreva um segundo parágrafo sobre isso.

III.Leia todo o texto novamente e escreva um terceiro parágrafo sobre os termos (palavras) que se opõem, como palavras de contraste. Neste ponto, você já pode dizer o que o texto está afirmando e negando. 
"Retrato", de Cecilia Meireles (2001), foi o primeiro texto trabalhado em sala de aula para mostrar alguns aspectos do Nível Fundamental de leitura, com vistas a capacitá-los quanto ao desejado norte, por meio de uma sequência de atividades que envolvceram ainda poemas em língua inglesa, desde Shakespeare à Walt Whitman e John Donne.

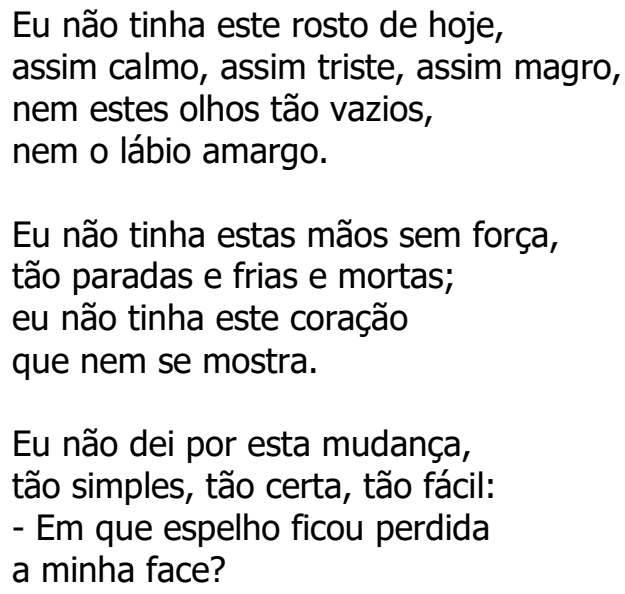

Depois da leitura do poema por um dos alunos, passamos a lhes perguntar sobre o que tinham apreendido em termos de sentido, verso por verso do início ao fim. Depois de inquiri-los, passamos a dissertar sobre o poema, sempre lhes fazendo perguntas, dando-lhes a voz para que se expressassem.

Nesse poema, percebe-se a afirmação da juventude e a negação do envelhecimento, quando o narrador relaciona o passado e o presente, o que ela costumava ser e o que ela é no presente. É através de um pressuposto lógico baseado em sua descrição do presente que se pode ver seu rosto, seu rosto não era calmo, triste, magro.

Os dois últimos lexemas (triste, magro) funcionam como figuras que trazem a temática do envelhecimento e suas consequências no físico (face) que denota também uma mudança psicológica. As evidências desse envelhecimento ainda estão relacionadas aos seus olhos que são "tão vazios" e no lábio que é tão amargo, o que significa que a vida era doce quando ela era jovem e sua aparência era de uma jovem bonita.

O narrador trabalha não só com as partes contidas em seu rosto, como os seus olhos, mas também com outras partes de seu corpo como suas mãos que agora são fracas, sem força, ainda, frias e mortas e seu coração que não se mostra. 
Tem-se o englobante, corpo físico, e os englobados aqui relacionados. O rosto funciona como termo englobante onde estão os englobados olhos e lábios. E assim, vai se tecendo a temática do envelhecimento em duas perspectivas: física e psicológica. Na estrofe 3, a última, que se pode ver uma linha chave quando o narrador admite não ter percebido a mudança pela qual passou. Este é o ponto crucial para se ver sua rejeição de seu envelhecimento, pelo menos no nível psicológico, quando ela diz que não viu essa transformação, como alguém que está se negando ao olhar-se no espelho, por não gostar de ver as marcas do tempo.

Não entramos numa análise minuciosa e mais aprofundada deste sujeito que ainda pode ser estudado como nostálgico, melancólico, tomado por uma paixão semiótica, numa crise existencial da busca de uma identidade em oposição à alteridade, da sua imagem que não é o próprio sujeito, mas o lugar do outro, conforme nos mostra Michel Foucault $^{2}$ (1994, p. 752-762). Por uma questão de tempo e nos limitando à demonstração do passo a passo para a leitura objetiva do texto, procuramos trabalhar apenas o nível superficial do sentido como ferramentas básicas.

A explicação de alguns termos que iam surgindo impulsionados pela interação com o grupo, no entanto, era inevitável, aproveitandonos do elemento curiosidade que surgia a medida que os diálogos iam se desenrolando. Assim, foi necessário explicar, por exemplo, de uma maneira não hermética, o conceito de narratividade, tão importante aqui, pois revela e apoia a tese inicial de que o poema afirma a juventude e nega o envelhecimento. A prova disso está nas duas últimas linhas, quando o narrador faz uma pergunta: "- Em que o meu rosto ficou perdido?". Ela age como alguém que não viu a mudança da juventude para o envelhecimento, porque ela não gostou da imagem que viu no espelho, porque em um nível mais profundo de leitura, ela estava com medo de sua alteridade, da imagem do "eu" que ocupava outro lugar.

Como o poema ilustra o nível fundamental da leitura, é mais fácil identificar o que é eufórico e disfórico. Todas as figuras que nos levam ao passado, exceto por seu rosto calmo, que pode indicar não apenas o envelhecimento, mas também a experiência, que tornaria o termo positivo, todos os outros lexemas assumem uma conotação negativa, disforizante como "triste", "amargo", "magro", referindo-se ao rosto dela, "vazio" relacionado aos olhos, "débil", "imóvel", "frio" e "morto" e um coração "oculto". Embora, no nível da aparência, a mudança por que passou é "tão simples, tão certa, tão fácil", no nível da imanência ela

\footnotetext{
${ }^{2}$ Debruçamo-nos no momento num estudo mais aguçado do poema de Meireles em que se procurará mostrar a identidade em oposição à alteridade em publicação futura.
} 
não queria que fosse, porque, novamente, no nível da aparência ela "finge" que não viu a mudança inevitável que o tempo pode fazer com todo mundo. Manter-se jovem, bonita e cheia de vida é o elemento eufórico, algo que o tempo não permitiu que fosse. O tempo, desta forma, é o adversário, o antagonista, o anti-sujeito em seu programa narrativo da vida.

As oposições são claras: passado versus presente, juventude versus envelhecimento e, num nível mais profundo de compreensão, identidade versus alteridade. Tudo isso gira em torno de dois planos: o estático e o dinâmico. O primeiro relacionado ao passado, como um retrato na parede e, outro, relacionado ao vigor da vida e que muda ao longo do tempo.

Para reforçar a explicação sobre o nível fundamental da leitura, vejamos agora o soneto 142, de William Shakespeare:

Love is my sin, and thy dear virtue hate, Hate of my sin, grounded on sinful loving, $\mathrm{O}$, but with mine, compare thou thine own state, And thou shalt find it merits not reproving, Or if it do, not from those lips of thine That have profaned their scarlet ornaments And sealed false bonds of love as oft as mine, Robbed others' beds' revenues of their rents. Be it lawful I love thee as thou lov'st those Whom thine eyes woo as mine importune thee. Root pity in thy heart, that when it grows Thy pity may deserve to pitied be. If thou dost seek to have what thou dost hide, By self-example mayst thou be denied! (Atkins, 2007: 348)

O narrador tem o "amor" como o termo eufórico e "ódio" como disfórico. Esta é, a propósito, a principal oposição no soneto. Há também um contraste no "meu pecado" em relação à "tua querida virtude", a afirmação do cinismo e a negação do idealismo. Movido pela paixão, o narrador apóia a rejeição, porque ele não se considera digno dela. Ele se auto-despreza por não ser capaz de evitar amá-la. Essa é a razão pela qual há a afirmação do amor (ele a ama) e a negação do ódio (ela o odeia). Ele acha que merece seu escárnio, seu desdém, seu desrespeito por causa de seu comportamento desagradável e não por causa de si mesmo. Ele também acredita que merece sua piedade, já que ele compartilha de sua imoralidade, seus maus hábitos, sua má conduta, sua iniqüidade. Todos esses termos se opõem à virtude. Sua sátira está 
em "Seja leal, eu te amo por tu desejares, quereres aqueles/ A quem os teus olhos cortejam como os meus te importunam". A ironia é que seu amor por ela é baseado em seu "amor pecaminoso" pelos outros. É isso que o manipula para sua admiração por ela.

Feitas estas demonstrações relacionadas ao nível fundamental de leitura, no passo a passo, chegamos ao nível narrativo. Siga os nossos passos, caro leitor:

IV. Identifique os personagens que aparecem no texto e nomeie cada um segundo sua importância no texto como S1, S2, S3, etc.

V. Escolha o personagem principal e concentre-se em suas ações dentro do texto, verificando o esquema narrativo da seguinte forma: manipulação - competência - desempenho - sanção.

VI. As manipulações são quatro: sedução, quando há um elogio. Provocação, quando há um desafio. Tentação, quando algo material é oferecido e intimidação, quando há uma ameaça.

VII. Escreva um quarto parágrafo descrevendo o tipo de manipulação que o personagem principal (Actante S1) usa para persuadir alguém no texto ou fora dele.

VIII.Escreva um quinto parágrafo sobre a competência do personagem principal (S1). Para que ele/ela seja considerado competente para realizar a performance, a ação, é necessário que ele/ela tenha quatro modalidades: querer fazer, dever-fazer, saber-fazer e poder-fazer. Portanto, este quinto parágrafo deve descrever se esse personagem principal é competente ou não. Se ele perder uma das modalidades, ele/ela não poderá realizar a performance, executar sua missão.

IX. Escreva um sexto parágrafo sobre o desempenho, a performance. 0 desempenho é a ação em si, o que o personagem principal faz ao longo do seu percurso. Descreva em detalhes.

X. Escreva um sétimo parágrafo sobre a sanção. A sanção é o julgamento que o personagem principal faz em relação ao seu próprio desempenho ou sobre a performance de outra pessoa. É a recompensa que o sujeito (pessoa) que fez a performance recebe daquela pessoa que the pediu para fazer a performance. Pode ser positiva ou negativa. Um presente, uma quantia em dinheiro, por exemplo, é uma sanção positiva. Um "obrigado", "você fez um bom trabalho", por exemplo, é também uma sanção positiva. Se a recompensa é algo material, então a sanção é positiva e pragmática. Se a "recompensa" é apenas um "obrigado", então a sanção é positiva e cognitiva. Se em vez de receber uma recompensa, como um prêmio no final de um campeonato, o sujeito 
(pessoa) recebe uma punição por não completar a apresentação, a sanção é negativa. Um "boo" pode ser uma forma de punição. Então, seu sétimo parágrafo deve descrever se houve uma sanção ou não. Se houve uma sanção, então você tem que explicar o tipo de sanção que foi.

XI. Escreva um oitavo parágrafo sobre o objeto modal usado pelo sujeito para realizar a performance em seu percusrso da busca de uma objeto de valor que quarda por traz de si um determinado valor. Objeto modal é um objeto mágico. Um bom exemplo é o espinafre que faz o Popeye competente para derrotar o Brutus. Um objeto de valor é o que guarda oculto um valor qualquer, dependendo do sujeito que o adquire. Por exemplo, um carro é um objeto modal, porque é um meio de transporte. Seu valor é, neste caso, utilitário. Na narrativa de Popeye, o espinafre é o objeto modal e o objeto de valor é a felicidade, porque ele conquista o amor de Olivia ao derrotar Brutus, tendo o espinafre que o capacita para realizar a performance.

XII. Escreva um nono parágrafo explicando se há um contrato fiduciário ou não. Um contrato fiduciário é estabelecido quando há uma proposta de um lado e a aceitação dessa proposta do outro lado (por parte da outra pessoa). O casamento é o melhor exemplo de contrato fiduciário, quando há a proposta de um lado e a aceitação da proposta de outro.

XIII.Escreva um décimo parágrafo sobre o trabalho do oponente, também chamado de anti-sujeito. O oponente é o antagonista, a pessoa que disjunge o sujeito de seu objeto de valor. Por exemplo, quando Brutus tira Olivia do Popeye, ele é o oponente no Programa Narrativo do Popeye, porque ele desvia o Popeye de seu objeto de valor. Ele tira a razão (Olivia) de sua felicidade. Nas narrativas, ou mesmo em um conto ou em qualquer outro texto ou narrativa em que se tenham muitos personagens, o cenário ideal é descrever o percurso de cada um delçes segundo sua ordem de importância. O protagonista, como chamamos na literatura é o actante sujeito principal na semiótica, o deuteragonista, geralmente, chamamos de oponente, o segundo personagem mais importante, uma vez que ele se opõe ao personagem principal e assim por diante, como a história do herói e do vilão.

Este é um modelo básico, passo a passo. Adentremos, agora, pois, ao nível discursivo e aos passos possíveis para, ao final, termos, por parte dos alunos, um artigo escrito de forma objetiva sobre o texto $x$ ou y. Essa é uma sugestão básica para tornar o aluno um pesquisador e escritor de artigos científicos, em outras palavras, para iniciá-lo na atividade de leitura e escrita não como um "fazedor" de redações, mas como um aluno iniciado como analista de discursos. 
XIV. Escreva um $11^{\circ}$ parágrafo sobre o ator ou atores. Os atuantes (aqueles que atuam em uma peça, um texto, um filme, etc.) que aparecem no nível narrativo agora são revestidos de um papel e nós os chamamos de atores. Descreva cada um deles, o espaço onde atuam e o tempo de sua ação.

$X V$. Escreva um $12^{\circ}$ parágrafo sobre as figuras, palavras que desencadeam os temas que convergem, ao final, para um tema principal do texto. Por exemplo, na letra da música "The Logical Song", de Roger Hodson (Supertramp), o narrador afirma: "Quando eu era jovem, parecia que a vida era tão maravilhosa. Um milagre, oh, foi lindo, mágico ${ }^{3 "}$, as palavras "maravilhoso", "milagre", "mágico" têm algo em comum. Elas repetem e fazem o tema da ludicidade, que é relacionado a algo lúdico, mostrando brincadeira espontânea e sem direção. Elas têm algo em comum que chamamos de "isotopia", a repetição de qualquer unidade semiótica. Uma isotopia fonética é a recorrência de fonomenas, como rima, assonância e aliteração. Uma isotopia prosódica é a recorrência do mesmo ritmo. Em uma história, detectamos uma isotopia quando há uma repetição de um traço básico de significado (sema); tal repetição, estabelecendo algum nível de familiaridade dentro da história, permite uma leitura/interpretação uniforme dela. Você pode fazer um esquema onde as figuras estão em uma coluna e os temas estão na outra coluna.

XVI Faça um quadrado semiótico (a estrutura elementar da significação) com a principal oposição (contraste) que você encontrou ao longo da análise que acabou de produzir. Por exemplo, no poema "Sozinho", de Edgar Alan Poe (1894-1895, p. 237), a principal oposição é a solidão versus a interação, (união, ajuntamento) e o quadrado semiótico é:

FIGURA I: Quadrado semiótico do isolamento e distanciamento social

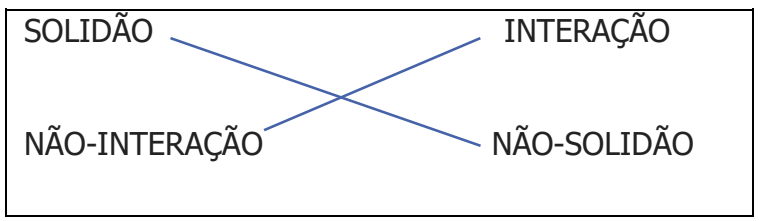

No entanto, podemos pensar esse sujeito que reconhece que desde

\footnotetext{
3 Tradução nossa para "When I was young, it seemed that life was so wonderful/A miracle, oh it was beautiful, magical/. Supertramp, Álbum: Breakfast in America, Data de lançamento: 1979. https://www.google.com/search?q=the+logical+song\&oq=the+logical+song\&aqs=chrome..69i57 j0l5.3231j0j7\&sourceid=chrome\&ie=UTF-8 visitado em: 02 abr. 2019.
} 
sua infância não tem sido como os outros eram, não tem visto como os outros viram, que não trouxe suas paixões de uma fonte comum, que nem tirou sua tristeza da mesma fonte, ou despertou seu coração para a alegria na mesma intensidade que os demais e que tudo que amou, amou sozinho como um sujeito diferente em relação aos idênticos outros:

FIGURA II: Quadrado semiótico da identidade e alteridade

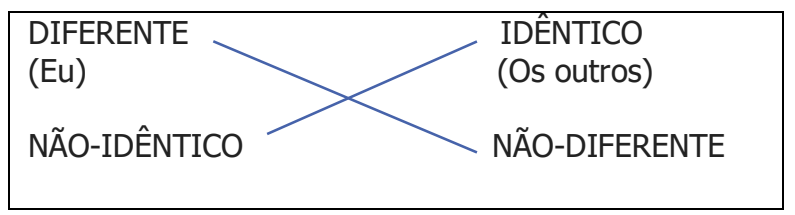

1. From childhood's hour I have not been

2. As others were; I have not seen

3. As others saw; I could not bring

4. My passions from a common spring

5. From the same source I have not taken

6. My sorrow; I could not awaken

7. My heart to joy at the same tone

8. And all I loved, I loved alone.

eight-syllable verses

É possível ter, em um nível mais profundo de leitura, outro quadrado semiótico, com a oposição principal como identidade versus alteridade, se considerarmos que estar sozinho é uma escolha feita pelo narrador.

FIGURA III: Quadrado semiótico do contrato social

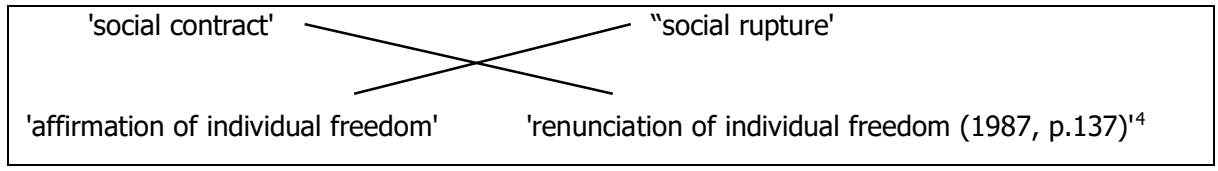

O quadrado semiótico projetado por Ronald Schleifer em seu livro "Greimas and the Nature of Meaning: Linguistics, Semiotics and Discourse Theory" (1987, p. 137) pode ser aplicado ao poema de Poe, porque mostra a ruptura com um contrato social de umn sujeito que procura a afirmação de uma liberdade individual e nega um contrato social pertinente à posição assumida. 
O narrador em "Alone" afirma sua liberdade individual, provocando uma quebra de contrato social por meio da opção por sua solidão em oposição ao convívio social. Esta configuração é a representação de um contrato social. Ao verificarmos o eixo dos contrários, solidão versus ajuntamento, a solidão é considerada eufórica, porque é por meio dela que o actante sujeito afirma sua liberdade individual. Estar envolvido com a sociedade significaria renunciar dessa liberdade.

FIGURA IV: Quadrado semiótico do isolamento e contrato social

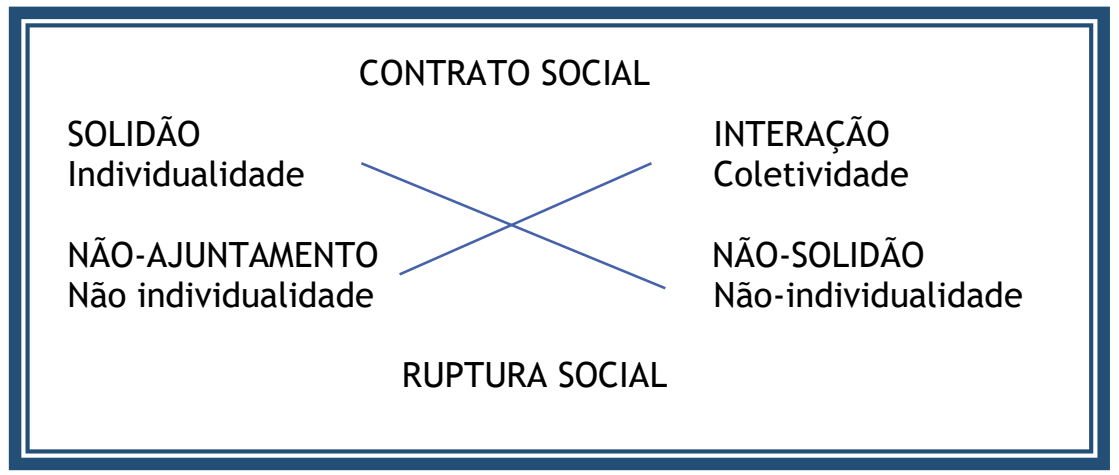

Na visão geral do quadrado semiótico, que é a estrutura elementar da significação, o termo contrato social funciona como intermediário da solidão e o convívio social e a rupture desse sontrato fiduciário de caráter social é o termo intermediário entre a opção de não convívio social e não solidão. Não conviver socialmente representa, assim, não renunciar de sua liberdade individual. Optar pela não solidão representa não afirmar a liberdade individual.

Após sua tese inicial, o narrador busca provar sua teoria de que ele não tem sido como os outros foram, e não tem visto como os outros viram, porque não pôde trazer suas paixões de uma fonte comum. Logo, sua fonte de inspiração é diferente. Ele é o diferente, "jogando" com o lexema "spring" que, em inglês, pode significar primavera, como o termo é mais conhecido, mas também pode significar "fonte de água. Eis aqui a diferença: suas emoções, seus sentimentos, sua maneira de ver o mundo, seu comportamento não são moldados por regras sociais, mas por ele mesmo. Essa é a Liberdade individual de que precisa. Temos, aqui, a configuração de um sujeito patêmico, cuja inspiração e diretrizes de vida vieram de uma fonte incomum. É esta fonte não ordinária, mas extraordinária, diríamos, que vai formar a isotopia do mistério, da escuridade, de um demônio em sua visão como vemos nos últimos versos. 
9. Then-in my childhood, in the dawn

10. Of a most stormy life-was drawn

11. From every depth of good and ill

12. The mystery which binds me still eight-syllable verses

13. From the torrent, or the fountain,

14. From the red cliff of the mountain,

15. From the sun that round me rolled

16. In its autumn tint of gold,

17. From the lightning in the sky

18. As it passed me flying by,

19. From the thunder and the storm,

20. And the cloud that took the form

21. (When the rest of Heaven was blue)

22. Of a demon in my view.

(POE 2004, p. 778)

Esta entidade reforça a isotopia misteriosa, posto que é uma espécie de mistura do que conseguiu extrair em sua juventude do bem e do mal, no arvorecer de uma vida tempestuosa. É aquele mistério que ainda o liga, o prende, com quem ainda mantém vínculo, como vemos nos versos 9-12. São dez, portanto, as fontes de sua inspiração, do ser que é no presente, que fazem parte do seu passado, de sua infância em relação à vida adulta: fonte incomum, conforme o verso 4, fonte sincrética das profundezas do bem e do mal, verso 11 , fonte da torrente e do chafariz no verso 13 , do penhasco avermelhado da montanha, verso 14 , do sol, verso 15, do relâmpado no céu, verso 17 , do trovão e da tempestade, verso 19, e da nuvem, verso 20, que toma a forma de um demônio em sua visão.

Ele trabalha com elementos que formam a isotopia figurativa da natureza a qual podemos opor à cultura negada por meio deo não-querer viver socialmente. É, também, um caso de uma defesa da identidade em oposição à alteridade, como no poema "Retrato" de Cecília Meireles.

A nuvem funciona como elemento que sofre uma metamorfose, ganha a forma de um demônio que perturba sua visão. Eis ai o lexema que denota a isotopia do mistério, em confluência com elementos, lexemas naturais que emitem efeitos sinestésicos em seu sincretismo ora eufóricos, caso do sol, do Firmamento em oposição, por pressuposição lógica, em oposição ao inferno, vistos pelos lexemas "Heaven" e "Demon", "good" e "ill".

Essa incompetência desse sujeito patêmico explicada pelo uso do verbo anômalo "could", seguido da negação "not". Ele não pôde, não foi capaz de trazer suas paixões de uma fonte comum. Esse /não-poder-fazer/ é uma situação patêmica, é o sujeito manipulador de deu /querer-serdiferente/. Sua escrita, desta forma, não segue o rumo comum, o óbvio, sugerindo uma resposta às críticas que alguém pode ter em relação a outro alguém que prefere ficar sozinho, ou não tem outra alternativa, já que suas 
perdas não Ihe permitiam viver com aqueles que ele amava, e essa é a razão pela qual tudo o que ele amava, ele amava sozinho.

Juntamente com as paixões, suas tristezas não poderiam ter sido trazidas de uma fonte comum, nem despertou seu coração para alegria no mesmo tom e, por essa razão, tudo o que ele amava, ele amava sozinho.

O lexema "sorrow" é definido por um sentimento de angústia profunda causado por uma perda e tem como oposto a palavra alegria, "joy", o contrário do desapontamento, ou de outro infortúnio sofrido por esse sujeito nostálgico, ou melancólico. Essa categoria semântica tristeza versus alegria e o lexema "alone", título de seu poema, dão coerência à sua posição de alguém que quer preservar sua identidade em oposição à alteridade. É essa emoção mista que causa o resultado de ser ou estar sozinho, de amar sozinho. É aqui que vemos a solidão versus coexistência, a individualidade versus coletividade, a particularidade versus totalidade.

Ao recuperar seus dias de infância, neste flashback literário, o narrador enfatiza todos os atributos de seu estado de alma isoladamente, o que é visto pela maioria das pessoas no nível da aparência como disfórico.

Ele justifica que ele é a soma, o resultado de uma vida tempestuosa, um produto de um sincretismo das coisas boas e da miséria, do bem e do mal, que sugere intenções malignas, na transformação da nuvem em um demônio, em oposição ao Céu. São estes os espaços que habitam os males e as coisas boas. E é exatamente essa complexidade, essa mistura de bem e mal que intriga esse narrador a ponto de deixá-lo em uma situação insolúvel. É essa falta de solução para o mistério que mantém o suspense de seu poema, como em uma história de detetive, quando é necessário resolver o enigma.

A palavra "still" denota essa passagem da infância para a idade adulta, dizendo que isso é algo que ainda persiste. É o tipo de sujeito que não consegue romper o vínculo com as experiências ruins do passado que Ihe fizeram ser o que é no presente. Desta forma os termos opostos estão misturados em um grande pólo que desencadeia tudo o que ele é.

É interessante como ele é capaz de transformar o disfórico em eufórico, dando ao bem e ao mal, ou as coisas boas e as más, as adversidades, um valor unificado que explica seu estado de alma, sua escolha de ser ou seu motivo de estar sozinho. É o mistério que ainda o prende, que ainda o mantém unido, o faz unido consigo mesmo, encontrando força em si mesmo, transformando os negativos em positivos. Portanto, o mistério é um termo importante relacionado ao sincretismo do bem e do mal, que tem duas funções aqui: impede-o de seguir em frente e, ao mesmo tempo, faz com que ele continue. 
Este mistério originou-se na relação das profundezas do que é bom e da miséria e está presente na torrente, na fonte, no penhasco vermelho da montanha, no sol, no outono, no relâmpago no céu, no trovão, na tempestade e na nuvem, que assumiu a forma de um demônio em sua visão. Todos esses lexemas são termos englobados que pertencem à Terra em oposição ao Céu. A nuvem é um fenômeno natural importante para determinar o equilíbrio do poema, já que é o intermediário entre o Céu e a Terra, como o mediador que assumiu a forma de um demônio em sua visão, que lhe causa essa "perturbação". Também é importante notar que a nuvem não era o próprio demônio, mas tomou a forma, representou em sua visão a disforia de sua vida, a razão pela qual ele era diferente dos outros, como alguém que se sente auto-comiseração, o único azarado em oposição à sorte de todos os outros, cujo lugar é um céu azul. Aqui podemos ver uma crítica do narrador para o Céu (Deus) em oposição ao mal, o demônio em sua visão, como alguém que diz que ele está sozinho, que não há Deus acima, ou ironicamente dizendo que a culpa está no demônio por ele estar sozinho e por amar sozinho.

A natureza em oposição à cultura é determinante de seu estado de alma, sua posição cultural, alguém que devido às perdas não tinha outra alternativa senão estar sozinho, estranho à sociedade, no nível da aparência. No nível da imanência textual, podemos dizer que ele termina seu poema delegando ao demônio a culpa ou a glória do que é apresentado no poema, reforçando a categoria semântica do mal em oposição ao bem, na representação do céu azul em oposição à nuvem, elemento nebuloso. A dicotomia entre a melancolia e a realidade permeia o poema, que se torna uma mistura de predição do que aconteceria e um relato do que aconteceu com um narrador que mostra o trauma de sua existência.

Essa mesma temática do isolamento versus o engajamento pode ser visto ainda na canção "No man is an Island" (1987) de John Donne.

FIGURA V: Quadrado semiótico da parcialidade e totalidade

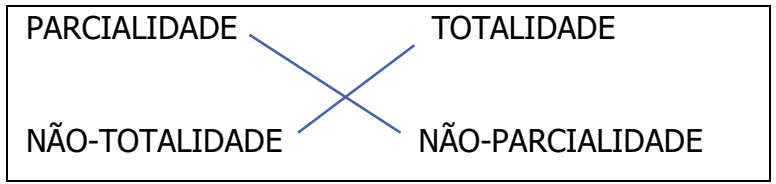


No man is an island,

Entire of itself,

Every man is a piece of the continent,

A part of the main.

If a clod be washed away by the sea,

Europe is the less.

As well as if a promontory were.

As well as if a manor of thy friend's

Or of thine own were:

Any man's death diminishes me,

Because I am involved in mankind,

And therefore never send to know for whom the bell tolls;

It tolls for thee.

Além desta oposição notória da parcialidade em relação à totalidade, percebe-se também a categoria semântica da interação em oposição ao isolamento:

FIGURA VI: Quadrado semiótico da interação e isolamento

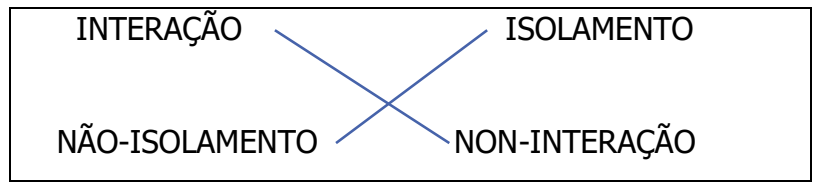

XVII. Escreva um último parágrafo explicando o quadrado semiótico e trazendo de volta a introdução do seu artigo analítico. No topo da praça, as palavras de contraste representam o eixo dos contrários e, no fundo do quadrado, as palavras contraditórias. Lembre-se de que essas oposições às vezes estão implícitas no texto e você deve descobri-las. Não se esqueça de mencionar as fontes que você usou para fazer sua análise, citou trabalhos.

Este foi o modelo passo a passo apresentado ao grupo de alunos, de forma mais simplificada, por uma questão de tempo, com a finalidade de Ihes fornecer os elementos básicos de análise, especialmente do nível fundamental, com alguns elementos do nível narrativo. Não foi possível apresentar o nível discursivo com mais exemplos de aplicabilidade.

The corpus: "O Bicho" (1986), a poem by Manuel Bandeira.

Vi ontem um bicho

$\mathrm{Na}$ imundice do pátio 
Catando comida entre os detritos.

Quando achava alguma coisa,

Não examinava nem cheirava:

Engolia com voracidade.

O bicho não era um cão.

Não era um gato,

Não era um rato.

O bicho, meu Deus, era um homem.

Esse corpus foi apresentado a um grupo de graduandos (4) e pósgraduandos (2). Em seguida, iniciou-se uma série de atividades que ocorreram em aulas regulares de Língua Portuguesa durante a primavera (2017) num total de quatro aulas, tempo que consideramos exíguo para a apresentação de uma teoria tão complexa. Foi esse, no entanto, o "espaço" que conseguimos no currículo oficial (plano de ensino) da professora de português da universidade americana onde fizemos as pesquisas, e é compreensível, pois ela tinha uma agenda a cumprir.

Dos doze escritos coletados, apresento 3 deles como modelos (as normas deste artigo, com páginas limitadas a quinze, ao total, não me permitem apresentar mais do que esses três ensaios sobre o poema) para mostrar quão profundamente os alunos se aprofundaram no sentido do poema após as atividades envolvendo o método passo a passo de leitura desenvolvidas em sala de aula.

Uma vez que os alunos ainda não conseguiam se expressar em sua totaslidade em Língua Portuguesa, oferecemos-Ihes a liberdade de optarem entre a utilização do código em Português ou inglês. Transcreveos seus trextos conforme a escrita original de cada aluno e, dentre alunos e alunas, por uma questão didática, vamos descrevê-los todos, independente de sexo, como "aluno", sempre nos referindo a ele ou ela no masculino.

Minha proposta aqui não é examinar a ortografia, gramática, pontuação ou algo semelhante, mas o próprio significado.

\section{Primeira escrita do aluno 1.}

"O poeta conta a sua experiência de ver um bicho e compara as ações do bicho com o comportamento dos homens. O poeta acha que os homens também são como os bichos, lutando na sujeira para sobreviver. Os homens são tão ganancioso que só sabem lutar para o recursos mas não sabem aproveitar as coisas que logram através da luta dura". 
O aluno tenta resumir o poema em português, assumindo que o homem é um animal: "O poeta conta sua experiência de ver um bicho". De fato, não é um animal, mas um homem se comportando como um animal, exatamente o oposto do que ele quis dizer ao escrever "e compara como ações de bicho com comportamento de homens". As ações não são executadas por um animal, mas por um homem. Ele também confunde o poeta com o narrador. No entanto, quando diz que o poeta pensa que os homens são como os animais, ele chega ao ponto, especialmente dizendo que esses homens lutam na terra para sobreviver. É realmente uma questão de sobrevivência que leva o homem a agir como um animal, embora ele não seja um animal. Seguindo esse pensamento, ele finalmente emite sua opinião sobre o comportamento dos homens, classificando-os como gananciosos em busca de recursos (dinheiro?).

E um resumo de um parágrafo, com uma opinião no final. $\mathrm{Na}$ segunda redação, no entanto, há uma melhora visível quando, em inglês, ele escreve:

\section{Aluno 1 , segunda escrita.}

"The poem under analysis is "O bicho" written by Manuel Bandeira. In this poem, the author affirmed that the image of the "bicho" in search for food in the garbage is like humans.

Generally throughout the text there is a dysphoric sense. Some representative words he used to provoke this sensation is "imundície", "detritos". Using these words, the author describes some unpleasant scene by which he compares the animal with the humans. This metaphor is by no means positive because of the contrast of "comida", "detrito" o "imundície". In the text there are three main characters. The "narrator", the "bicho" and the "humans". The narrator describes the scene of the "bichos" looking for food and relates it to the "humans". Through the description of the "voracidade" of the "bichos" and the environment of the yard where the action of the "bichos" take place, the narrator manipulated the readers' sensation and guided it to compare with the same characteristics of "humans". The manipulation is the efforts that the "bichos" make to find food.

In this text the metaphor of the author is stablished upon the basis of the same competence to find food and the "voracidade". They obtain their food by the "voracidade" and in the unpleasant environment. And finally the sanction the author give is negative at the cognitive level, because even the rewards the "bichos". At the manipulation level is food the stony contrast between "food" and the "bichos" action that the just swallow it without smelling it, makes the image of blindness and greed stood out". 
Não só a quantidade de linhas, mas sua organização em parágrafos e o uso ou aplicação de alguns termos explicados durante a sequência didática nos mostram que houve um aprofundamento em sua visão do texto. Embora ele não use o termo "narrador", mas autor, ele aplica o nível fundamental dizendo que a imagem do "bicho" procura comida e a relaciona com os "humanos".

Ele assume, como o outro aluno cuja escrita veremos em seguida, que o homem é um animal que age como os humanos. No mesmo nível, ele identifica a disforia e apresenta sua evidência através dos lexemas "imundície", "detritos", que nos levam à isotopia da imoralidade através da animalização do homem que se torna moralmente impuro, cerimonialmente impuro. Este homem, deste ponto de vista, é o reflexo da sociedade. Ele afirma que existe uma metáfora positiva por causa do contraste de "comida", "detrito" ou "imundície". De fato, a metáfora está relacionada ao homem se comportar como um animal e a "comida" é eufórica, mas não se pode dizer o mesmo a respeito de "restos" e "impureza", que são termos disfóricos.

No terceiro parágrafo ele tenta aplicar o nível narrativo dizendo que existem três personagens principais no poema. O que se tem aqui é o narrador que trabalha como observador e como homem. $O$ animal não está lá, mas um homem que age da mesma maneira. O que podemos dizer é que, nesse caso, esse homem tem um papel actancial dual: ele age como um animal, mas continua sendo um homem. O fato de o narrador apresentar a dúvida usando o termo "bicho" no início do poema não retira a natureza de um homem para esse "bicho", pois ele descobriu que "o bicho não era um cão. Não era um gato, Não era um rato" e sua surpresa, ao final", quando diz, "O bicho, meu Deus, o bicho era um homem". Esta é a prova de que ele identificou um homem vivendo no estado de um animal como um cachorro, um gato ou mesmo um rato que se nutre dos detritos no lixo.

O narrador não descreve a cena dos "bichos" à procura de comida, mas "o bicho", e ele o relaciona com os "humanos", até descobrir que não é um animal, mas um homem.

O uso do lexema "voracidade" expressa a maneira como ele se alimenta dos restos mortais por sua fome violenta, e não é um assunto de manipulação para o leitor. A manipulação relacionada ao leitor é a sedução, porque um poema é uma obra de arte que chama a atenção do leitor por suas figuras de línguagens, como a metáfora homem igual animal, e sua linguagem figurativa, sonoridade, sinestesia etc. É claro que há um efeito de sentido provocado no leitor que nosso aluno analista chama de "sensação do leitor". Essa sensação é igual ao efeito de sentido ao qual Greimas se refere e ao que Roland Barthes chama de ilusão referencial. É 
a primeira impressão que temos de algo que acabamos de ler, como as notícias de um jornal. Esse não é o sentido em si, mas o efeito de sentido. Para chegar ao sentido propriamente dito, é necessária uma leitura mais profunda do texto, uma análise minuciosa, é preciso se fazer uma ecografia do texto como o médico faz em um paciente.

Mas o estudante analista diz que "a manipulação é o esforço que os "bichos" fazem para encontrar comida". O que talvez ele quis dizer com isso é que foi o instinto de sobrevivência que levou o homem a agir como um animal, procurando comida em qualquer lugar que pudesse, para matar vorazmente sua fome e continuar vivendo. Nesse cenário, podemos dizer que a fome funcionou como sujeito/objeto de manipulação por meio da intimidação, pois ninguém quer morrer por falta de comida. Do ponto de vista do destinador e do destinatário, podemos falar sobre outra manipulação. É a provocação, porque o enunciador nos leva a um desafio de decifrar o significado do poema e, como parte dessa sociedade, refletir sobre as necessidades de outras pessoas e sobre o nosso próprio comportamento ou reação diante dos níveis de desigualdades na sociedade em que pertencemos. Encontramos o homem agindo como um animal e nos vemos, ao mesmo tempo, muitas vezes, como sujeitos indiferentes às necessidades dos outros.

O aluno tem razão em dizer que há uma sanção negativa e cognitiva do narrador para o homem, pelo menos no início do poema, quando o identifica como animal. Essa mesma sanção, em um nível mais profundo, é aplicada à sociedade no nível da enunciação.

$O$ fato de engolir sem cheirar vem com a pressão de uma outra força imanente, a fome intensa, a necessidade de sobreviver e tem a ver com a maneira como come: vorazmente. É a intensa e imensa fome que determina sua maneira selvagem de se alimentar.

\section{Primeira escrita do aluno 2.}

- "The poem is told from the point of view of the author examining a person rummaging for food. At first glance he thinks it is an animal when in reality it is a man. The man was so desperate for food that he didn't care what he was eating and his mannerisms were animal like. The author, in the end was astonished by the fact that this "animal" was actually a man. In desperate times people will resort to desperate measures in order to survive"

O que se pode ver como um efeito significativo quando se olha para o terceiro texto objeto de análise, o primeiro texto analítico deste segundo 
aluno é que é uma espécie de resumo de acordo com a sua compreensão. Não há um suporte de uma teoria para afirmar que é uma análise, mas uma interpretação simples em que, ao final, o aluno tenta mostrar a moral da história, ou seja, conclui, e agora podemos ver sua opinião, que "em tempos de desespero as pessoas recorrerão a medidas desesperadas para sobreviver", em que dá ao narrador a atitude de alguém que se comporta feito um animal.

Ele começa concentrando-se na perspectiva do autor e não se concentra no texto, ou na atividade do narrador posto em discurso. Segundo o aluno, esse autor é um sujeito de dúvida, pois ele não sabe se o homem é um homem ou um animal no início de sua escrita. A partir deste momento, o aluno fala sobre o estado do homem.

Percebe-se que não é a opinião do narrador sobre o homem-bicho, mas a impressão do aluno. Considerando que o narrador é, de fato, um sujeito de observação que dá uma sanção negativa ao homem que observa, pois ele o confunde com um animal, podemos considerar nosso aluno como narrador agora e, desse ponto de vista, ele descreve os estados de alma desse sujeito, "remexendo na comida", um homem confuso com um animal, "desesperado pela comida", não importa o que ele coma, agindo como um animal.

Ele, o aluno, finalmente mostra a surpresa do autor no final "pelo fato de que esse" animal "era um homem". O uso das aspas na palavra "animal" mostra que ele assume a interpretação de que o homem não é um animal, mas que pode agir como tal quando está em situações desesperadoras ao precisar sobreviver.

\section{Escrita dois do primeiro aluno}

- "The text affirms that there is a hungry being searching for food because it is hungry. It initially denies that that this being is a human or even could be a human. What human would be searching for food amongst the trash?

The euphoric aspect of the text, I suppose, include the idea that this being, this bicho is finding food to satisfy its hunger. This is a positive thing. Contrastingly, the text exposes dysphoria upon revealing the bicho is actually a human rummaging through and eating garbage.

Oppositions occurs when the narrator intends to identify this bicho? Is it a dog? A cat? A rat? The outcome opposes these theories because it is actually a human

The subject of the poem, the bicho, is provoked by his own need to survive. The will to survive is the challenge presented to him. Hunger works as the threat and intimidation and is standing in his way of survival. The 
food, the garbage, the scraps act as the temptation. Something he desires to satisfy hunger. His actions are therefore manipulated by these actions.

I'm not entirely sure how competence comes into play here. Perhaps it is as follows: the bicho knows that he must find food to survive, he wants to survive, he knows that he can satisfy hunger by finding food and knows how and he is able to do so by searching in the rubbish.

The performance is the action of the bicho searching for food.

I don't really know what this level is about. But let me give it a try.

Oppositions: main themes

\begin{tabular}{|c|c|} 
Marginalization \\
Non-member
\end{tabular} $\begin{gathered}\text { civized } \\
\text { Member of society } \\
\text { non-marginalization }\end{gathered}$

"O bicho, meu Deus, era um homem", "presents the" surprise that the bicho is actually a human. It indicates that the narrator is surprised over this fact. It appears he feels humans should not be rummaging through thrash to find food. This indicates that the bicho-homem is a marginalized member of the narrator's society with regards to access to food.

Esta quarta redação objeto de nossa análise, segunda redação deste segundo aluno não pode mais ser definida como um resumo do texto. É uma análise objetiva do poema com início, desenvolvimento e conclusão, dividida em parágrafos e melhor organizada que a primeira escrita. Contempla a percepção de que existe um "ser à procura de comida porque está com fome".

Embora o aluno analista explique "o bicho" como um "ser", usando o pronome neutro "ele", ele coloca esse "ser" na condição de um animal, porque o pronome do caso reto "ele" se refere a objetos, coisas, animais de estimação ou até mesmo para um bebê quando ainda não sabemos o sexo dele.

O aluno analista aplica o nível fundamental de leitura, seguindo o método passo a passo, quando identifica que no poema há a negação da humanização do homem e a afirmação da animalização dele. Ele ela apóia sua tese inicial dizendo que "Inicialmente nega que este ser é humano ou até poderia ser humano".

O uso dos lexemas "ser" e "ele" mostra sua dúvida sobre a identidade do sujeito-ator ao longo do poema. O estudante analista considera o personagem como um ser humano e, ao mesmo tempo, declara sua condição de animal que procura comida no lixo.

A pergunta "Que humano procuraria comida no lixo?" Nos leva a pensar nesse ser marginalizado no contexto dessa sociedade específica e 
encontra apoio quando, ao final do ensaio, o estudante analista elabora o quadrado semiótico, atingindo o nível discursivo e profundo de significado. No entanto, ele continua em dúvida quato à verdadeira identidade do homem, pois insiste em usar o pronome neutro "it", em vez de "he", indicando que sua opinião é a de que o homem é um bicho.

Ainda trabalhando no nível fundamental e seguindo o método passo a passo para a leitura e escrita, ele associa o estado de euforia ao "encontrar comida para satisfazer sua fome" e a disforia através de sua condição de animal, já que ele é um ser humano. Esses estados do homem focalizados pelo narrador do texto, desprovido de comida, como associado ao bicho-homem ou homem-bicho, mostram a narratividade no poema, a sucessão de estados de um sujeito ao longo do texto e é eufórico porque a comida é o objeto modal de sua sobrevivência. Portanto, sobreviver é eufórico e perecer é disfórico. O objeto de valor por trás da comida é a manutenção da vida em oposição à morte.

Apesar de não empregar as oposições diretamente, o estudante analista afirma que "As oposições ocorrem quando o narrador pretende identificar esse bicho: Isto é um cão? Um gato? Um rato?". Por isso, dizendo que "o resultado se opõe a essas teorias porque na verdade é um ser humano", ele deixa a possibilidade de se opor à animalização do homem com a humanização de um animal em aberto. Sua opinião, finalmente, é que o "bicho" cuja identidade é desconhecida (é um cachorro? Um gato? Um rato? ") é, "na verdade, um humano".

Essas perguntas são uma espécie de recurso usado pelo enunciador (uma posição agora assumida pelo aluno analista) para despertar reflexões em nossas mentes (como enunciatários discursivos/destinatários internos da mensagem) e é outra evidência da capacidade do aluno de aprofundar sua percepção do sentido dentro do poema, usando a teoria e o método passo a passo da leitura e escrita. Por outro lado, o fato de perguntar se as oposições ocorrem com a intenção do narrador de identificar "o bicho" mostra que tem dúvidas sobre como verificar as oposições no texto.

Podemos sintetizar os lexemas "cachorro, gato, rato" como formadores da isotopia da animalização do homem que se opõe à humanização do animal, no nível da aparência. "O bicho" parece ser um cachorro, um gato, um rato, mas ele é, de fato, "um humano, um homem", diz 0 aluno.

O quadrado semiótico da veridicção elaborado por Greimas \& Courtés (1979, p. 488) é apropriado para aplicar-se a esse poema, pois mostra o nível de aparência oposto ao nível de imanência do texto, que mantém o segredo entre o "ser" e o "não parecer"e a mentira entre o "parecer" e o "não-ser": 
FIGURA VII: Quadrado semiótico da veridiç̧ão

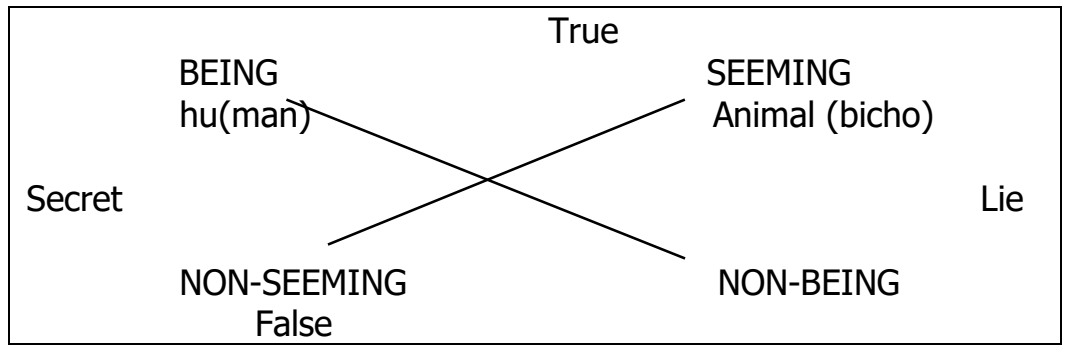

A verdade está entre o ser humano e o fato de ele parecer um animal, o bicho que, de fato, ele não é, porque é levado a essa condição, àquele estado disfórico pela rejeição e indiferença da sociedade.

A falsidade está entre o "não parecer" ser homem e o "não ser" um animal, por conta dele ser humano e ter sido levado ao estado de um animal por sua marginalização diante dos olhos das pessoas que passam nas ruas, ao verem a cena e não fazerem nada para ajudá-lo ou até reconhecê-lo como irmão, passando de largo como na parábola do bom samaritano ou mesmo no poema de John Donne, "No man is an Island" como vai defender o poeta inglês de que somos parte integrante da humanidade.

Deste ponto de vista, a animalização está relacionada à degradação a que ele é levado e se encontra, procurando o elemento de sua sobrevivência no lixo, e sua humanização está relacionada à sua real condição de homem vítima da indiferença por parte de uma sociedade fria e calculista. Esse estado de marginalização é muito bem detectado pelo estudante analista através de sua síntese na base elementar da significação, o quadrado semiótico que ele produz.

O aluno analista aplica o nível narrativo de leitura quando nos leva a inferir que foi "a própria necessidade de sobreviver" que o levou à situação de um "bicho", pois ele precisava de "comida" para sobreviver. Quando ele diz que "A vontade de sobreviver é o desafio apresentado a ele", ele está identificando a manipulação por provocação. Quando inteligentemente ele diz que "a fome funciona como ameaça e intimidação e está no seu caminho de sobrevivência", vemos que ele percebe a manipulação por intimidação no poema. Quando ele finalmente afirma que "A comida, o lixo, os restos agem como tentação", ele está falando sobre a manipulação por tentação, embora não haja outro sujeito que ofereça comida ao homem, mas o próprio lixo oferece isso, o que se torna numa ironia.

Os lexemas "o lixo", "os restos", que funcionam como formadores de "alimentos", são a representação dos restos alimentares que as pessoas normalmente, em culturas como a do Brasil nas áreas rurais, oferecem a 
porcos, galinhas, cachorros e gatos. Esse alimento restante mostra, ironicamente, as escórias, os destroços da sociedade.

A segunda fase do esquema narrativo é posta em jogo pelo aluno, embora ele admita não ter certeza disso, dizendo que "o bicho sabe que precisa encontrar comida para sobreviver, quer sobreviver, sabe que ele pode satisfazer a fome encontrando comida e sabe como, e pode fazê-lo procurando-a no lixo". É isso que chamamos de competência, quando o sujeito quer-fazer, deve-fazer, pode-fazer e saber-fazer a ação delegada pelo destinador. Nesse caso, o destinador não é uma pessoa, mas sua necessidade de sobreviver. É isso que o leva a entregar-se na condição de um animal para continuar vivendo.

Essa competência é adquirida pelo "homem-animal" porque ele quer comer, sente que precisa comer, sabe como conseguir o que comer. Quando ele procura no lixo, ele mostra que pode encontrá-la. Conseqüentemente, ele é um sujeito realizado no desempenho da sobrevivência, pois, para ser considerado uma pessoa competente é preciso estar revestido da competência volitiva (querer-fazer) e deôntica (dever-fazer), além da pragmática (poder-fazer) e cognitiva (saber-fazer).

O aluno definiu e identificou o terceiro elemento do esquema canônico da narrativa ao dizer: "A performance é a ação do bicho em busca de comida". Ele simplesmente não mencionou a sanção, positiva e pragmática, uma vez que o homem foi recompensado pela comida que encontrou, o que chamamos de auto-sanção.

Não apenas os dois níveis explicados pela sequência de atividades do PI, mas também o terceiro, o nível discursivo, quando ele elabora o quadrado semiótico, fechando e resumindo sua análise, encontrando e colocando no quadrado o eixo dos contrários, "marginalização" versus "civilizado" e o eixo dos contraditórios "não civilizado ou membro da sociedade" e "não marginalização" semonstram o quanto sua percepção do sentido do texto foi ampliada após o método passo a passo de análise. Embora não tenha havido tempo para apresentar o nível discursivo de leitura aos alunos pelo curto período de tempo que obtivemos no currículo, ele pôde mencionar o ator e o espaço em que a performance ocorreu.

Sua conclusão é a evidência final de sua competência no desenvolvimento deste ensaio analítico sobre "O Bicho", de Manuel Bandeira, mostrando que a teoria e o método passo a passo funcionaram bem como um objeto modelo para seu desempenho, capacitando-o com a competência para ser um sujeito realizado no processo de leitura e escrita (análise) do poema.

Obviamente, uma análise detalhada e mais completa é algo que requer mais tempo e experiência com a teoria e com o domínio de sua linguagem hermética, mas seu desempenho é suficiente para vermos quão 
objetivo e profundo ele passou a ser em relação à interpretação deste texto específico, após as atividades didáticas de sua apresentação passo a passo.

\section{CONCLUSÃO}

A pesquisa mostra com base nos resultados das análises dos alunose de nossas reflexões sobre estas análises que o método "passo a passo" para leitura e escrita como um projeto para ajudar os alunos nos níveis de graduação e pós-graduação a melhorar seus desempenhos relacionados à interpretação e redação de textos funcionou bem.

Estes resultados vêm confirmar pesquisas preliminares realizadas com estudantes do ensino fundamental e ensino médio no Brasil por meio de orientação de duas dissertações de mestrado do PROFLETRAS em que se aplicou a proposta em sala de aula de algumas escolas públicas e outras atividades relativas em projetos de iniciação cinetífica que se tornaram artigos publicados em jornais e revistas especializadas no período de 20142020.

Alguém pode dizer que qualquer teoria usada após uma primeira prática de interpretação e intervenção vai melhorar o desempenho dos alunos. É verdade, mas também é verdade que não existe tal proposta quando a experiência passa a ser uma análise mais objetiva, à luz de um método passo a passo de leitura e escrita inspirada pela teoria semiótica de Greimas. Em outras palavras, os níveis de leitura propostos pela semiótica greimasiana são apresentados por alguns poucos professores em algumas escolas no Brasil por meio do livro de Platão \& Fiorin, "Para Entender o Texto" (2003), mas não há uma proposta de ler e escrever em etapas, como a possibilidade de escrever um ensaio crítico, por exemplo, como aqueles examinados neste artigo, quando se mostra, pela análise comparativa da primeira e da segunda redação, a competência pragmática do aluno na apreensão e, sobretudo, da aplicabilidade de uma teoria na perspectiva da objetividade.

E o mesmo fenômeno de ampliação da percepção do sentido no interior do poema ocorreu com os doze escritos coletados nesta pesquisa. De fato, houve uma melhor compreensão do significado do poema após as atividades. O espaço, todavia, deste artigo, não nos permite demonstrar estes outros resultados, mas ficou latente o interesse de que o velho desejo de Greimas de "popularizar" a ciência, beneficiando o número maior possível de pessoas se cumprisse por estas e outras pesquisas subsequentes. 


\section{REFERÊNCIAS}

AMORIN, Ana Paula Teixeira. Semiótica em sala de aula: Uma proposta para a ampliação do modo de ver (ler) o texto. Dissertação (Mestrado em Letras), Programa de Pós-Graduação Mestrado Profissional em Letras, Universidade Federal do Mato Grosso do Sul. Três Lagoas, 2016.

ARRIVÉ, Michel. (1972). Systématique des isotopies. In Essais de sémiotique poétique, A. J. Greimas (ed.), pp. 80-106. Paris: Larousse.

ATKINS, Carl, D. Shakespeare's Sonnets: With Three Hundred Years of Commentaries. Associated University Press. Cranbury, New Jersey, Rosemont Publishing and Printing Corp. 2007.

BANDEIRA, Manuel. O Bicho. In: Poesia Completa e Prosa Vol. Único. Editora Nova Aguilar. São Paulo, 1986.

CORTI, Maria. An Introduction to Literary Semiotics. Translated by Margherita Bogat and Allen Mandelbaum. Indiana University Press/Bloomington and London. 1978, from the original "principi della comunicazione letteraria (1976), Bompiani, Milan, Italy.

DONNE, John. "No Man is An Island". In: John Donne. Devotions upon Emergent Occasions. Edited by Anthony Raspa. New York, Oxford University Press, 1987.

DONELI, Maurício. O poema, a crônica, o conto, o romance e os ecos intertextuais e semióticos da busca do sentido do texto. Dissertação (Mestrado em Letras), Programa de Pós-Graduação - Mestrado Profissional em Letras, Universidade Federal do Mato Grosso do Sul. Três Lagoas, 2020.

GOMES, M. A.; NAKAMURA, I. I. D.; SANTOS, V. Experiência didática por meio da semiótica aplicada em Canção para minha morte, de Manuel Bandeira.IV SIMPÓSIO NACIONAL DE LETRAS E LINGUÍSTICA: LINGUAGEM, LITERATURA E ENSINO: DESAFIOS E POSSIBILIDADES. De 25 a 28 de agosto de 2015. Anais... Catalão, UFG, 2015. p. 862-874. Disponível em: https://conpeex.ufg.br/up/850/o/ANAIS_SINALEL_ COMPLETOS_Vers\%C3\%A3o_Final.pdf.

GIORNO, J. J. Estratégias de leitura da imagem no ensino de linguagem: competência comunicativa multimodal. Dissertação (Mestrado em Letras), Programa de Pós-Graduação - Mestrado Profissional em Letras, Universidade Federal do Mato Grosso do Sul. Três Lagoas, 2017. 
GREIMAS, Algirdas Julien e COURTÉS, Joseph. Dicionário de Semiótica. Trad. Editora Cultrix. São Paulo, 1973.

GREIMAS, Algirdas Julien. Enssais de Sémiótique poétique. Libraire Larousse, 1972. Poética. Translated by Heloisa de Lima Dantas. Editora Cultrix.

GREIMAS, Algirdas Julien. Description and Narrativity: The Piece of String. In: New Literary History 20 (1989), S. 615-626.

GREIMAS, Algirdas Julien. The Social Sciences. A Semiotic View. Foreword by Paolo Fabri and Paul Perron. Translation by Paul Perron and Frank H. Collins. University of Minnesota Press, Minneapolis, 1990.

MEIRELES, Cecília. Antologia Poética. Rio de Janeiro: Nova Fronteira, 2001.

NAKAMURA, I. I. D.; GOMES, M. A.; SANTOS, V. Semiótica aplicada ao ensino: uma experiência didática com o texto não verbal. IV SIMPÓSIO NACIONAL DE LETRAS E LINGUÍSTICA: LINGUAGEM, LITERATURA E ENSINO: DESAFIOS E POSSIBILIDADES. De 25 a 28 de agosto de 2015. Anais... Catalão, UFG, 2015. p. 502-513. Disponível em: https://conpeex.ufg.br/up/850/o/ANAIS_SINALEL_COMPLETOS_Vers \%C3\%A3o_Final.pdf.

POE, Edgar, Alan. "Alone" - 1894-1895 - The Works of Edgar Allan Poe, vol. 10: Poems, ed. E. C. Stedman and G. E. Woodberry, Chicago: Stone and Kimball (10:138, and p. 237)

RASTIER, François. Meaning and Textuality. Translated by Frank Collins and Paul Perron. University of Toronto Press, Toronto, Buffalo, London. 1997. Original in: French Sens et Textualité (Paris Hachette) 1989.

SANTOS, Valdenildo \& AMORIN, A. P. T. Gênero Histórias em Quadrinhos, Matacognição e Semiótica como Motivação para Leitura e Escrita Críticas na Sala de Aula. In. Portuguese Language Journal, A double-blind referred journal dedicated to current research on the teaching and learning of Portuguese, Number 11, Fall 2017. Guess Editor Roza Bizarro. AOTP American Organization of Teachers of Portuguese.

SANTOS, Valdenildo. Semiótica como objeto modal para uma leitura crítica. Abralin em cena, p. 1-15, 2012.

O ensino de Inglês por meio da música via programa radiofônico. Diálogos Pertinentes, Franca, v. 8, n 1, p. 48-69, jul./dez. 2012b. Disponível em: http://publicacoes.unifran.br/index.php/dialogos pertinentes/article/viewFile/639/510 
. Na interface das estratégias de leitura instrumental e a leitura crítica: reflexões e sugestões. Diálogos Pertinentes, Franca, v. 9, n० 2, p. 62-83, 2013. Disponível em: http://publicacoes.unifran.br/index.php/ dialogospertinentes/article/view/778/602.

. Semiótica e a formação de professores de português e literatura de Três Lagoas. SIELP 2014. Anais... v. 3, no 1. Uberlândia: Edufu, 2014. Disponível em: http://www.ileel.ufu.br/anaisdosielp/wp-content/uploads/ 2014/11/78.pdf

; AMORIN, A. P. T. Gênero histórias em quadrinhos, metacognição e Semiótica como Motivação para Leitura e Escrita Críticas na Sala de Aula. Portuguese Language Journal, no 11, Fall 2017.

; AMORIN, A. P. T.; QUEIROZ, G. P. Metacognição e semiótica como objetos modais para a autonomia e abertura da percepção na Escola Pública de Três Lagoas. CONELIN - CONGRESSO DE ESTUDOS DA LINGUAGEM, 4, 2016. Cornélio Procópio. Caderno de resumos. Cornélio Procópio: UENP, 2016b. p. 272-291. Disponível em: https://drive. google.com/file/d/0B-aXc3hIvevpcGZ6bXhUTTNpXzQ/view.

; SANTOS, A.; HELENA, T.; AMORIN, A. P. Leitura crítica na Escola Pública Luiz Lopes de Carvalho. Diálogos Pertinentes, Franca, v. 11, no 1, p. 27-52, jan./jul. 2015.

SAVIOLLI, F. P. \& FIORIN, J.L. Platão e Fiorin: Para Entender o Texto. Leitura e Redação. Ática, São Paulo.

SCHLEIFER, Ronald. A.J. Greimas and the Nature of Meaning: Linguistics, Semiotics and Discourse Theory. Croom Helm, London \& Sydney, Australia, 1987.

Recebido em: 12/10/2021

Aceite em: 04/12/2021 